\title{
Fabrication of Very High Resistivity Si with Low Loss and Cross Talk
}

\author{
Y. H. Wu, Albert Chin, Senior Member, IEEE, K. H. Shih, C. C. Wu, C. P. Liao, S. C. Pai, and C. C. Chi
}

\begin{abstract}
We have used proton and $\mathrm{As}^{+}$implantation to increase the resistivity of conventional $\mathrm{Si}(10 \Omega-\mathrm{cm})$ and $\mathrm{Si}$-on-quartz substrates, respectively. High resistivity of $1.6 \mathrm{M} \Omega-\mathrm{cm}$ is measured that is close to intrinsic Si and semi-insulating GaAs. Very low loss and cross coupling of $6.3 \mathrm{~dB} / \mathrm{cm}$ and $-79 \mathrm{~dB} / \mathrm{cm}(10 \mu \mathrm{m}$ gap $)$ at 20 GHz are measured on these samples, respectively. The very high resistivity and improved rf performance are due to the extremely fast $\sim 1 \mathrm{ps}$ carrier lifetime stable even after a $400{ }^{\circ} \mathrm{C}$ annealing for $1 \mathrm{~h}$. Little negative effect on gate oxide integrity is also observed as evidenced by the comparable stress-induced leakage current and charge-to-breakdown for $30 \AA$ oxides.
\end{abstract}

Index Terms-Cross talk, high resistivity $\mathrm{Si}, \mathrm{RF}$ loss.

\section{INTRODUCTION}

$\mathbf{I}$ $\mathrm{N}$ spite of the rapid tec hnology evolution for Si rf transistors [1]-[5], the most important issue to realize high performance MMIC is the passive transmission line loss due to much lower substrate resistivity compared to semi-insulating GaAs [6]-[9]. The low resistivity $(10 \Omega-\mathrm{cm})$ results in substantial energy loss and dielectric attenuation that impose a severe limitation on transmission lines and inductors at rf frequency. Although high resistivity Si (1-10 k $\Omega-\mathrm{cm})[10]-[14]$ has been studied, the loss is still relatively high due to limited resistivity as compared with GaAs. Further, few papers have mentioned the low resistivity related cross coupling that is important for low-noise and power device integration and mixed signal IC. In this work, we have studied both transmission line loss and cross coupling on our developed extremely high resistivity $\mathrm{Si}$ of 10 $\mathrm{K}-1 \mathrm{M} \Omega$-cm fabricated by ion implantation. We have used $\mathrm{As}^{+}$ implantation on Si-on-quartz (SOQ) and high-energy proton implants to penetrate the entire Si [15] to overcome the problem of limited implant depth in our previous study [16]. The proton implantation has little effect on oxide integrity that can be integrated into VLSI back-end process.

\section{EXPERIMENTAL}

Conventional $10 \Omega$-cm Si substrates and SOQ wafers with a $2000 \AA$ top Si on $350 \mu \mathrm{m}$ thick quartz are used in this study. Proton and $\mathrm{As}^{+}$implantation are performed on standard $\mathrm{Si}$

Manuscript received December 20, 1999; revised March 30, 2000. This work was supported by the National Science Council of Taiwan under Contract 89-2215-E-009-044. The review of this letter was arranged by Editor C. Wann.

Y. H. Wu, A. Chin, K. H. Shih, and C. C. Wu are with the Department of Electronics Engineering, National Chiao Tung University, Hsinchu 300, Taiwan, R.O.C. (e-mail: achin@cc.nctu.edu.tw).

C. P. Liao is with the Electronics Research Service Organization, Industry Technology Research Institute, Hsinchu 300, Taiwan, R.O.C.

S. C. Pai and C. C. Chi are with the Department of Physics, National Tsing

Hua University, Hsinchu 300, Taiwan, R.O.C.

Publisher Item Identifier S 0741-3106(00)06300-X
TABLE I

MEASURED REsistivity AFTER As ${ }^{+}$or PROTON IMPLANTS ON DIFFERENT SUBSTRATES

\begin{tabular}{|c|c|c|c|c|}
\hline \multirow[t]{2}{*}{ Substrate } & \multirow[t]{2}{*}{ SOQ } & \multirow[t]{2}{*}{ SOQ } & \multicolumn{2}{|c|}{ Conventional Si Conventional $\mathrm{Si}$} \\
\hline & & & Substrate & Substrate \\
\hline $\begin{array}{l}\text { Implantation type } \\
\text { and dose }\left(\mathrm{cm}^{-2}\right)\end{array}$ & None & $\begin{array}{l}\mathrm{As}^{4} \\
10^{16}\end{array}$ & $\begin{array}{c}\text { Proton } \\
10^{15}\end{array}$ & $\begin{array}{c}\text { Proton } \\
10^{16}\end{array}$ \\
\hline $\begin{array}{c}\text { Resistivity }(\Omega \text {-cm) } \\
\text { As-implanted } \\
\text { Resistivity }(\Omega \text {-cm })\end{array}$ & 10 & 36,000 & 7,200 & $1.6 \times 10^{6}$ \\
\hline $400^{\circ} \mathrm{C}$ annealed & 10 & 32,000 & 6,600 & $1.2 \times 10^{6}$ \\
\hline
\end{tabular}

and SOQ with doses of $10^{15}$ to $10^{16} \mathrm{~cm}^{-2}$, respectively. To meet the requirement of penetrating the entire $\mathrm{Si}$, a proton energy of $10 \mathrm{MeV}$ is required that gives an implanted depth of $698 \mu \mathrm{m}$. To study the thermal stability of implanted $\mathrm{Si}$, $\mathrm{As}^{+}$and proton implanted wafers were annealed at 400 and $600{ }^{\circ} \mathrm{C}$ in nitrogen ambient for $1 \mathrm{~h}$. Coplanar transmission lines with $200-1000 \mu \mathrm{m}$ length and coupled transmission lines with $1000 \mu \mathrm{m}$ length and $10-60 \mu \mathrm{m}$ spacing are fabricated on various processed substrates using $1 \mu \mathrm{m}$ thick Al with $30 \mu \mathrm{m}$ width. Conventional Si substrate with $1.5 \mu \mathrm{m}$ thermal oxide was also used as references. Two-port $s$-parameters up to 20 $\mathrm{GHz}$ were measured using HP8510B network analyzer with ground-signal-ground probes. RF loss and cross coupling are extracted from the measured s-parameters after de-embedding from a dummy pad. Pump-probe measurement generated by femto-second laser pulse is used to obtain the carrier lifetime from reflectance response [16], [17]. Stress-induced leakage current (SILC) and charge-to-breakdown $\left(Q_{B D}\right)$ are measured for $30 \AA$ oxides to study the influence of gate oxide integrity by ion implantation.

\section{RESULTS AND DISCUSSION}

We have first measured the resistivity from current-voltage $(I-V)$ characteristics and summarized in Table I. The high resistivity after ion implantation may be due to implantation created high defect densities that effectively trap free carriers and increase resistivity. The higher resistivity obtained by $\mathrm{As}^{+}$implantation than proton, at the same dose of $10^{15} \mathrm{~cm}^{-2}$, is due to the heavier mass of $\mathrm{As}^{+}$and resultant higher damage and traps in Si. The measured 1.6 M $\Omega$-cm resistivity after proton implantation is close to GaAs and intrinsic $\mathrm{Si}$. The high resistivity stable after $400^{\circ} \mathrm{C}$ annealing for $1 \mathrm{hr}$ can be considered to integrate into VLSI back-end process.

We have further evaluated transmission line loss. As shown in Fig. 1, the loss decreases monotonically as increasing resistivity, and proton implanted Si owns the very low loss of $6.3 \mathrm{~dB} / \mathrm{cm}$. The small difference between SOQ with and without implant 


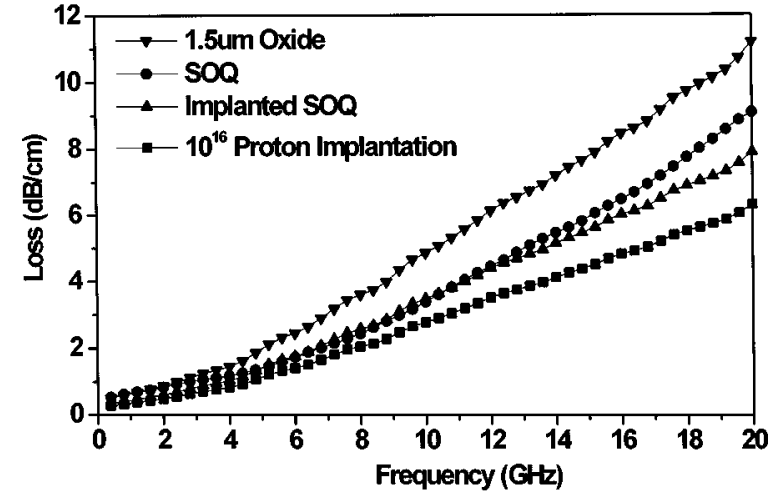

Fig. 1. Transmission line loss for various substrates with different resistivity. The transmission lines length, width, spacing, and Al metal thickness are 1000 $\mu \mathrm{m}, 30 \mu \mathrm{m}, 10 \mu \mathrm{m}$, and $1 \mu \mathrm{m}$, respectively.

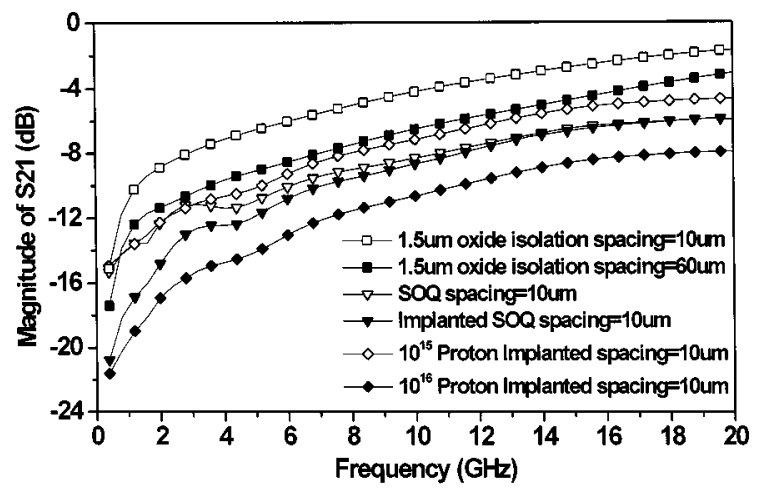

Fig. 2. Cross coupling for various substrates with different resistivity.

is due to the thin top $\mathrm{Si}$ that has a large depletion region by $\mathrm{Al}$ contact and thus improves the loss. The measured loss in this work is very competitive with published data in literature that proves implantation is a prominent process technology to reduce loss even we use a thinner $\mathrm{Al}$ line compared to other studies.

We have studied the implantation effect on cross coupling. As shown in Fig. 2, the coupling effect becomes worse as decreasing spacing from $60 \mu \mathrm{m}$ to $10 \mu \mathrm{m}$ for conventional Si (10 $\Omega-\mathrm{cm})$ with $1.5 \mu \mathrm{m}$ oxide. The strong coupling suggests that the $1.5 \mu \mathrm{m}$ oxide is still insufficient to obstruct the E-M field penetration. The cross coupling can be greatly reduced by the using $\mathrm{As}^{+}$implanted SOQ or proton implanted Si. The proton-implanted wafer shows the best coupling resistance of $-79 \mathrm{~dB} / \mathrm{cm}$ that is due to the extremely high resistivity shown in Table I. The close value between SOQ with and without implant may be due to the depletion effect by Al line.

To study trap recombination rate, we have measured the carrier lifetime from reflectance spectra. As in Fig. 3, carrier lifetimes of 1.1 and $1.3 \mathrm{ps}$ are measured for as-implanted and $400{ }^{\circ} \mathrm{C}$ annealed $\mathrm{Si}$, respectively, which suggests that high resistivity can be maintained as long as frequency is less than $1 \mathrm{THz}$. The high defect density and fast recombination rate can trap free carriers that give high resistivity and improved of performance. The reason why no signal can be measured after $600{ }^{\circ} \mathrm{C}$ annealing is due to the recrystallization produced long lifetime beyond measurement range.

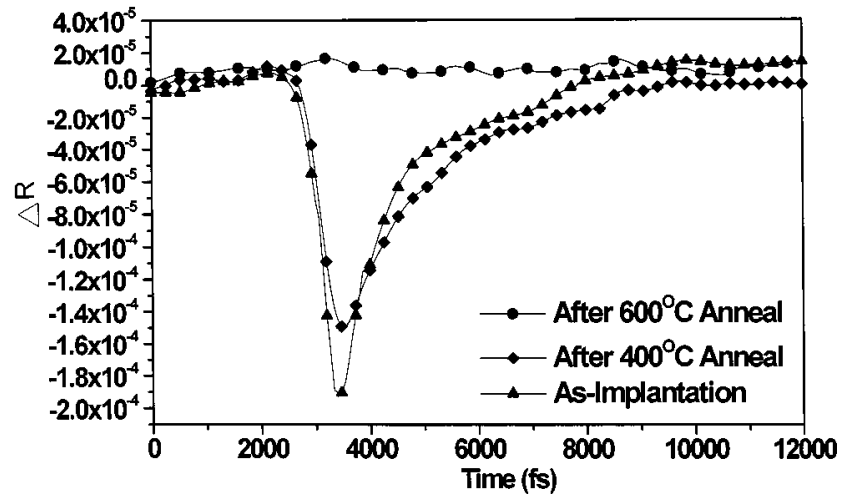

Fig. 3. Reflectance spectra of proton-implanted and different temperature annealed samples.

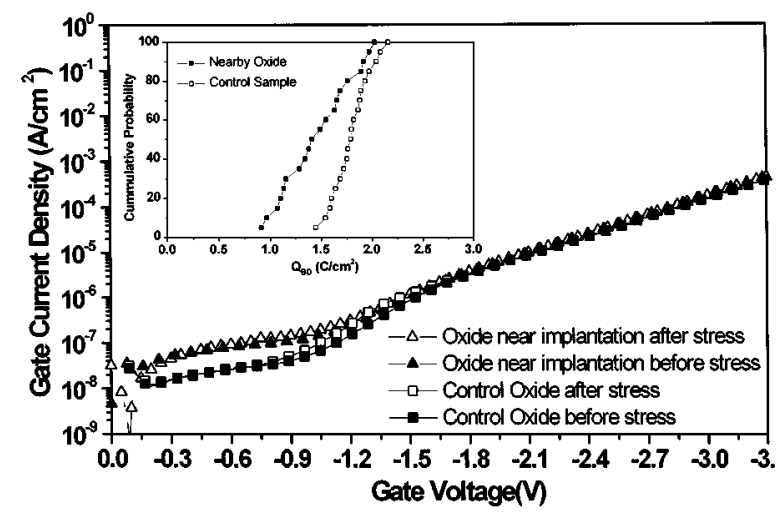

Fig. 4. Stress-induced leakage current and charge-to-breakdown distribution for control MOS devices and devices nearby implantation region. The oxide thickness is $30 \AA$.

We have further studied the proton implantation on gate oxide integrity [18], [19] that is very important for process integration. Fig. 4 shows the $J-V$ characteristics of $30 \AA$ oxides before and after stress and the cumulated $Q_{B D}$ distribution. As shown in Fig. 4, proton implantation has little effect on SILC for oxides nearby implantation region under a metal mask even after a $-4.0 \mathrm{~V}$ stress for $1000 \mathrm{~s}$ with a total charge injection of $2 \mathrm{C} / \mathrm{cm}^{2}$. In contrast, the MOS capacitors with direct implantation show high resistivity behavior that is due to the damaged $\mathrm{Si}$ substrate. The little side effect by proton implantation is also evidenced by the comparable $Q_{B D}$ of devices nearby implantation region with control MOS capacitors, which is also consistent with little SILC influence by implantation. The slightly lower $Q_{B D}$ of nearby MOS devices may be due to proton scattering into the metal mask with proximity contact on $\mathrm{Si}$ and damaging the underneath MOS capacitors. Further process development is required for thick metal pattern directly on backend dielectrics.

\section{CONCLUSIONS}

We have achieved high resistivity and extremely low loss and cross coupling, which is due to $\sim 1$ ps lifetime stable after $400{ }^{\circ} \mathrm{C}$ annealing. This process is compatible with current VLSI back-end process with little side effect on gate oxide integrity. 


\section{ACKNOWLEDGMENT}

The authors would like to thank T. S. Chao and L. B. Chen at the National Nano-Device Laboratory.

\section{REFERENCES}

[1] R.-H. Yan et al., "89-GHz $f_{T}$ room temperature silicon MOSFET's," IEEE Electron Device Lett., vol. 13, pp. 256-258, May 1992.

[2] S. P. Voinigescu, S. W. Tarasewicz, T. MacElwee, and J. Ilowski, "An assessment of the state-of-the-art $0.5 \mu \mathrm{m}$ bulk CMOS technology for RF applications," in IEDM Tech. Dig., 1995, pp. 721-725.

[3] I. Yoshida, "2-GHz power MOSFET technology," in IEDM Tech. Dig., 1997, pp. 51-54.

[4] C. K. King et al., "Integratable and low base resistance $\mathrm{Si} / \mathrm{Si}_{1-x} \mathrm{Ge}_{x}$ hetero-junction bipolar transistors using selective and nonselective rapid thermal epitaxy," in IEDM Tech. Dig., 1995, pp. 751-754.

[5] E. Morifuji et al., "Future perspective and scaling down roadmap for RF CMOS," in Symp. VLSI Technol., 1999, pp. 163-164.

[6] J. N. Burghartz, D. C. Edelstein, K. A. Jenkins, and Y. H. Kwark, "Spiral inductors and transmission lines in silicon technology using copper-damascene interconnects and low-loss substrate," IEEE Trans. Microwave Theory Tech., vol. 45, pp. 1961-1968, Oct. 1997.

[7] S. Yang et al., "Characteristics of trenched coplanar waveguide for high resistivity Si MMIC applications," IEEE Trans. Microwave Theory Tech., vol. 46, pp. 623-629, 1998.

[8] R. A. Johnson et al., "Comparison of microwave inductors fabricated on silicon-on-sapphire and bulk silicon," IEEE Microwave Guided Wave Lett., vol. 6, pp. 323-325, 1996.
[9] J. Y. C. Chang, A. A. Abidi, and M. Gaitan, "Large suspended inductors on silicon and their use in a $2 \mu \mathrm{m}$ RF amplifier," IEEE Electron Device Lett., vol. 14, pp. 246-248, 1993.

[10] A. C. Reyes, S. M. El-Ghazaly, S. J. Dorn, M. Dydyk, and D. K. Schoder, "Silicon as a microwave substrate," in MTT-S Tech. Dig., 1994, pp. 1759-1762.

[11] J. N. Burghartz et al., "Monolithic spiral inductors using a VLSI Cu damascene technology and low loss substrates," in IEDM Tech. Dig., 1996, pp. 99-102.

[12] Y. J. Yoon et al., "Design and characterization of multilayer spiral transmission-line baluns," IEEE Trans. Microwave Theory Tech., vol. 47, pp. 1841-1847, 1999.

[13] J. B. Muldavin and G. M. Rebeiz, "30 GHz tuned MEMS switches," in MTT-S Tech. Dig., 1999, pp. 1511-1514.

[14] D. Eggert et al., "A SOI-RF-CMOS technology on high resistivity SIMOX substrates for microwave applications to $5 \mathrm{GHz}$," IEEE Trans. Electron Devices, vol. 44, pp. 1981-1989, Nov. 1997.

[15] C. Liao et al., "Forming local semi-insulating regions on silicon wafers by proton bombrdment," in DRC Dig., 1998, pp. 80-81.

[16] A. Chin, K. Lee, B. C. Lin, and S. Horng, "Picosecond photoresponse of carriers in Si ion-implanted Si," Appl. Phys. Lett., vol. 69, pp. 653-655, 1996.

[17] F. E. Doany, D. Grischkowsky, and C. C. Chi, "Carrier lifetime versus ion-implantation dose in silicon on sapphire," Appl. Phys. Lett., vol. 50, pp. 460-462, 1987.

[18] A. Chin et al., "Device and reliability of high- $\mathrm{K} \mathrm{Al}_{2} \mathrm{O}_{3}$ gate dielectric with good mobility and low $D_{i . t}$," in Proc. Symp. VLSI Tech., 1999, pp. $135-136$.

[19] A. Chin et al., "The effect of native oxide on thin gate oxide integrity," IEEE Electron Device Lett., vol. 19, pp. 426-428, Nov. 1998. 